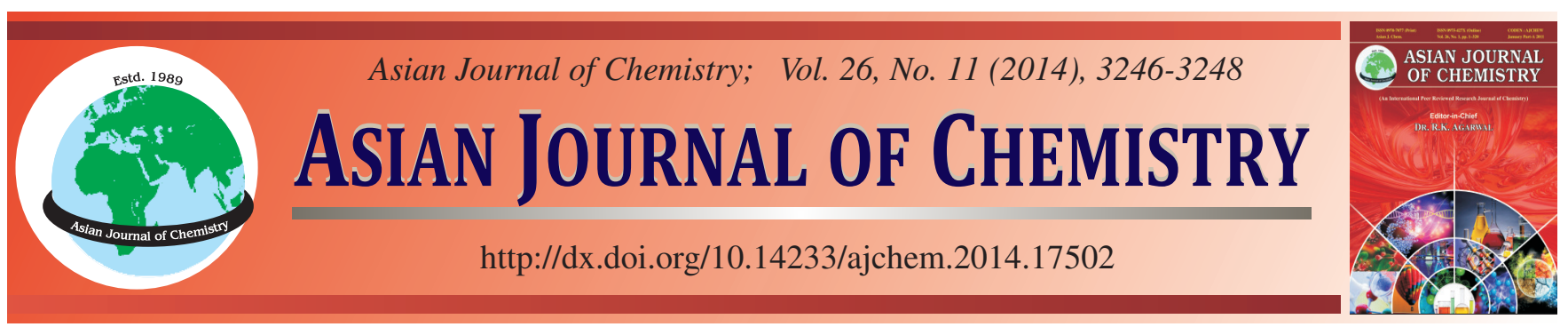

\title{
Influence of Material on Membrane Fouling and Cleaning Results of Mustard Tuber Wastewater Treatment by Membrane Bioreactor
}

\author{
HongXiang Chai ${ }^{1,2, *}$, Luwei Guo ${ }^{1,2}$, Yinghua Wei ${ }^{1,2}$, Jun Du $^{1,2}, \mathrm{~J}_{\mathrm{iAN}} \mathrm{Zhou}^{1,2}$ and Qiang He ${ }^{1,2}$
}

${ }^{1}$ Key Laboratory of Three Gorges Reservoir Region's Eco-Environments, Ministry of Education, Chongqing University, Chongqing 400045, P.R. China

${ }^{2}$ National Centre for International Research of Low-Carbon and Green Buildings, Chongqing University, Chongqing 400045, P.R. China

*Corresponding author: Tel/Fax: +86 23 65120980; E-mail: chaihx@cqu.edu.cn

When treating mustard tuber wastewater by membrane bioreactor (MBR), the membrane may be easily contaminated,in which process the membrane material is one of the major factors. To make it clear how the material affects the membrane fouling, four groups of experimental study were designed and carried out, respectively using the PVDF and PP membranes under the same conditions to find out which membrane was better in case of PVDF and PP membrane for the Membrane Bioreactor. And eight groups of tests were carried out to find out the optimal way for membrane cleaning. The results showed that, when controlling biofilm density at $30 \%$, water temperature at $8-12{ }^{\circ} \mathrm{C}$, dissolved oxygen at $4-5 \mathrm{mg} / \mathrm{L}$ and the suction pump inhaled $10 \mathrm{~min}$ and stopped for $3 \mathrm{~min}$, the contamination of the PP membrane was worse than the PVDF membrane in the treatmentof mustard tuber wastewater by membrane bioreactor. Meanwhile, it turned out that physical cleaning method had high efficiency to resume the membrane flux and the membrane flux can be resumed above $90 \%$ if cleaned by the $0.5 \%$ sodium hypochlorite solution.

Keywords: Cleaning, Fouling, Material, Membrane bioreactor, Mustard wastewater.

\section{INTRODUCTION}

Mustard tuber wastewater presents a challenge to conventional biological treatment process owing to the high salinity which is known to produce inhibitory or toxic effects on microorganism not acclimatizing to high salinity and high salt concentrations ( $>1 \%$ ) have been demonstrated to lead to the loss of activity of cells $\mathrm{s}^{1-3}$. The treatment of mustard tuber wastewater has become a significant focus in worldwide research fields.

At present membrane bioreactors (MBRs), as a combination of the activated sludge process and membrane separation, has been extensively researched and applied for anaerobic biological treatment of high salinity wastewater both in China and abroad due to its advantages including stable and high effluent quality, being hardly affected by sludge bulking, gathering large amounts of microbes and absolute removal of bacteria $^{4-8}$. Besides above strengths, membrane bioreactors are considered promising for high salinity mustard tuber wastewater treatment as it can be operated at high salt concentrations.

However membrane fouling, as a major factor, limited the widespread application of MBRs for the treatment of high salinity mustard tuber wastewater. Membrane fouling deteriorates the permeability of the membrane, leads to frequent membrane replacement and a necessity for cleaning which consequently increases energy consumption and operating costs and decreases membrane life-span ${ }^{9-11}$. Thus the mechanisms of membrane fouling and cleaning strategies have become the focus areas in MBRs research ${ }^{12}$. Many studies have been carried out recently aiming to investigate the influencing factors of membrane fouling.

Various factors have proven to affect membrane fouling in MBRs, including membrane aeration intensity ${ }^{13,14}$, mixed liquor suspended solid (MLSS) concentration ${ }^{15}$, food-to-microorganism ratio ${ }^{16}$, solid retention time ${ }^{17,18}$ and permeate flux ${ }^{19}$. But previous studies only focused on operational factors. In addition to these operational affecting factors, membrane material has also been thought to affect membrane fouling in MBRs. The material determines the surface characteristics of the membrane, making it a major factor affecting the membrane fouling. A severely fouled membrane must be cleaned and it is always costly. The cleaning strategy includes physical cleaning and chemical cleaning ${ }^{20}$. The paper aims to study the effects of membrane material on membrane fouling and 
cleaning in the process of mustard tuber wastewater treatment by membrane bioreactor.

\section{EXPERIMENTAL}

Experimental set-up: A schematic of the MBR experimental equipment in this study is shown in Fig. 1. The effective volume of the reactor was $4 \mathrm{~L}$, with a size of $1.08 \mathrm{~m} \times 0.75 \mathrm{~m}$ $\times 0.6 \mathrm{~m}$ (length $\times$ breadth $\times$ height). The reactor was made of steel plate, which is welded together. The equipment consists of two zones, the biota zone and the membrane patch zone. The biota zone was filled with semi-soft biofilm filler and the biofilm density was $30 \%$ while the membrane patch zone was filled with hollow fiber membrane modules. At the bottom of the reactor a pipe (DN200) was lied there to aerate.

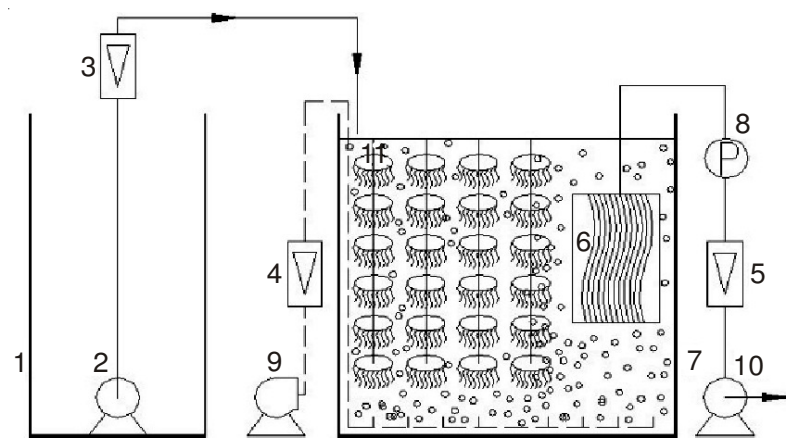

Fig. 1. Flow diagram of the experiment. 1 regulating tank, 2 pump, 3-5 flow-meter, 6 membrane module, 7 compound MBR reactor, 8 pressure gauge, 9 aeration pump

The MBR experimental equipment worked in this way: the wastewater, inputting continuously and outputting intermittently, was firstly pumped into the reactor from the regulating tankby the suction pump,then flowed past thebioticzone and the membrane patch zone, finally flow out of the reactor. The membrane flux was measured by flow-meter.

Experimental procedure: The MBR experimental equipment worked in this way: the wastewater, inputting continuously and outputting intermittently, was firstly pumped into the reactor from the regulating tankby the suction pump,then flowed past thebioticzone and the membrane patch zone, finally flow out of the reactor. The membrane flux was measured by flow-meter.

\section{RESULTS AND DISCUSSION}

Effect of material on the membrane fouling: The downward trend of membrane flux for the PP and PVDF membrane are shown in Fig. 2, respectively. The membrane were adopted in two reactors and there were no cleaning. As illustrated in Fig. 2, the reactor using PVDF membrane gradually tended to stabilize after $50 \mathrm{~min}$ in which process the membrane flux descended from initiative $31.92-11.32 \mathrm{~L} / \mathrm{m}^{2} \mathrm{~h}$. As a contrast, the other one tended to stabilize after $15 \mathrm{~min}$ in which process the membrane flux descended from initiative $15-6 \mathrm{~L} / \mathrm{m}^{2} \mathrm{~h}$. Comparing the descending ratio of the membrane flux between the PP and PVDF membrane under the same condition, it was discovered that the contamination ratio of PP membrane was higher than that of PVDF membrane. When the dimension of the membrane hole was equal, the water yielded by the reactor

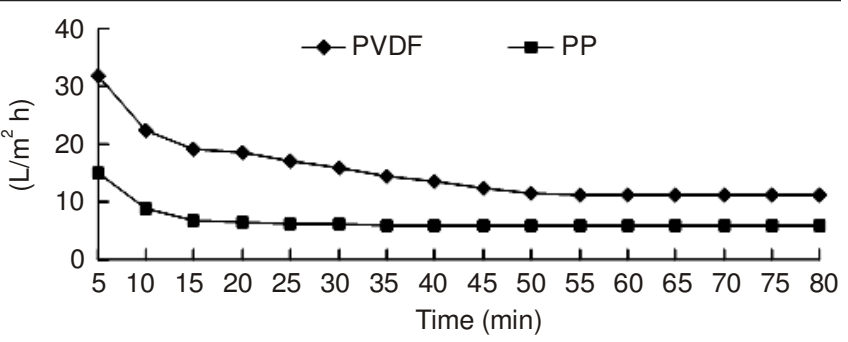

Fig. 2. Variations and contrast of the membrane flux

using PP membrane was far less than the one using PVDF membrane. Therefore a conclusion can be made i.e., the PP membrane is easier to be contaminated by mustard tuber wastewater.

When the reactor kept operating for $24 \mathrm{~h}$, the PP membrane and the PVDF membrane were took out to do scanning electron microscope and a contrast was made between the SEM photographs which were screened before and after the membrane were contaminated. Fig. 3 depicted the comparison of PP membrane before and after it was contaminated. The SEM photograph of contaminated PP membrane shows that: (1) A thick layer of stickumwas clinging to the membrane surface. (2) From the membrane surface, pore blocking can be seen clearly owing to the surge pressure of the membrane of MBR. (3) A layer of suspended sludge was also clinging to the membrane surface, but the sludge and the stickum were separated. And the compact sludge layer was kind of compressed. When all these phenomenon depicted above appeared, the membrane had been seriously polluted and the effective aperture of the membrane had decreased. Therefore, the flow velocity increased and a number of small granular material deviated the streamline of the suspended sludge mixture, finally settled down on the membrane surface with dissolved organic matter. Simultaneously, it was also discovered that sludge floc sedimentated to the same side of membrane cylinder and distributed in strip scattered shapes. Magnifying the interface of floc and membrane surface, it showed that the sludge floc clung to the membrane surface which appeared after the strickum clung to the membrane surface. But where no suspended sludge clung to membrane surface, the strickum layer was apparently thicker which illustrated that the clinging process of dissolved matter can be prevented by the clinging process of suspended sludge floc.
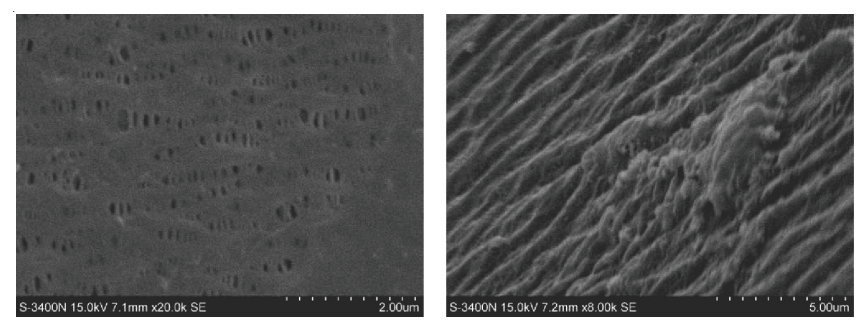

Fig. 3. SEM photographs of the new PP membrane and the fouling one

On the basis of above analysis, a conclusion can be made under the same condition of no long-term cleaning, the membrane fouling of PP membrane was worse, the membrane was covered by the sludge layer and the membrane flux declined seriously. 
Fig. 4 showed the comparison of PVDF membrane before and after it was contaminated. It can be seen that the membrane pore is blocked by the contaminant. Analyzing the reasons, it was considered that in this way at the initial stage of filtration, as the resistance increased sharply, membrane pore blocked and cake layer increased rapidly, which leaded to the sharp decline of the membrane flux. When the reactor operated in the $50 \mathrm{~min}$, membrane pore blocking and cake layer had been basically formed and membrane flux was relatively stable. Right this moment, membrane pore blocking and cake layer took the dominant position during the filtering process.
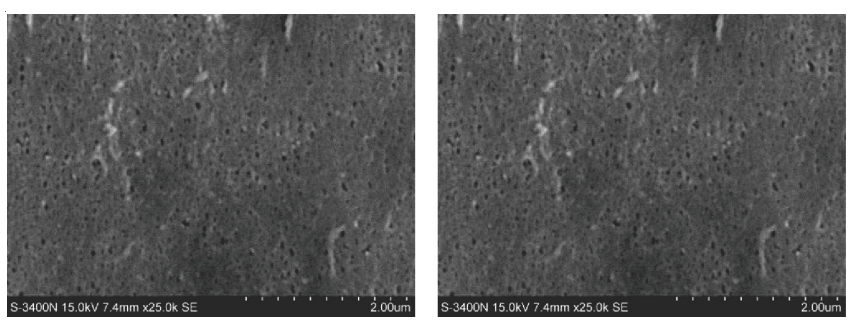

Fig. 4. SEM photographs of the new PVDF membrane and the fouling one

Experiment on optimal cleaning way: When the reactor kept operating for $24 \mathrm{~h}$, the PP membrane and PVDF membrane were took out, then cleaned in physical and chemical ways separately and every time the membrane was cleaned and the recovery of membrane flux was monitored. The results shown in Table-1, after cleaned in physical way, the membrane flux of PP membrane and PVDF membrane resumed to 61.94 and $55.74 \%$ of their initial membrane flux, respectively. After washing by using $2 \%$ of $\mathrm{NaOH}$ solution and soaked in clean water for $2 \mathrm{~h}$, the membrane flux of PP membrane and PVDF membrane resumed to 66.61 and $75.73 \%$ of their initial membrane flux, respectively. But after washing by soaking in $0.5 \%$ of $\mathrm{NaClO}$ solution for $24 \mathrm{~h}$ and soaked in clean water for $2 \mathrm{~h}$, the membrane flux of PP membrane and PVDF membrane resumed to 93 and $92.26 \%$ of their initial membrane flux, respectively. But in case of washing by soaking in $1 \%$ of $\mathrm{HCl}$ solution for $24 \mathrm{~h}$ and soaked in clean water for $2 \mathrm{~h}$, the membrane flux of PP membrane and PVDF membrane resumed to 83.2 and $84.47 \%$ of their initial membrane flux, respectively. It can be seen from the above analysis that washing in physical way can resume the membrane flux effectively and washing in the way of using $0.5 \%$ of $\mathrm{NaClO}$ solution can resume the membrane flux above $90 \%$. However, physical cleaning always requires manual work which is costly and makes the operation of membrane bioreactor more complicated.

\begin{tabular}{lcc}
\multicolumn{3}{c}{ TABLE-1 } \\
\multicolumn{3}{c}{ PARAMETER OF MEMBRANEMODULES } \\
\hline \multicolumn{1}{c}{ Item } & PVDF membrane & PP membrane \\
\hline Initial flux & 31.9 & 15 \\
Flux before cleaning & 11.32 & 6.02 \\
Flux after cleaning & 19.76 & 8.32 \\
Physical wash $+2 \% \mathrm{NaOH}$ & 21.25 & 11.36 \\
Physical cleaning+0.5\% NaClO & 29.67 & 13.84 \\
Physical cleaning $+1 \% \mathrm{HCl}$ & 26.54 & 12.67 \\
\hline
\end{tabular}

\section{Conclusion}

Comparing the membrane fouling during the operating process between the PP membrane and the PVDF membrane it was discovered: under the same running period, the PVDF membrane, other than the PP membrane, had lower membrane declining ratio, smoother membrane surface and higher initial membrane flux. Analyzing the resuming condition of membrane flux after cleaned in different ways, it was discovered that: cleaning in physical way can effectively resume the membrane flux and cleaning in the way of using $0.5 \%$ of $\mathrm{NaClO}$ solution can resume the membrane flux above $90 \%$. When treating mustard tuber wastewater by an MBR, it is more economic and more effective to use PVDF membrane.

\section{ACKNOWLEDGEMENTS}

This work is supported by the National Science Foundation Program of China, Grant No. 51008318 and the 111 Project, No. B13041.

\section{REFERENCES}

1. A.R. Dincer and F. Kargi, Process Biochem., 36, 901 (2001).

2. F. Kargi and A.R. Dincer, Enzyme Microb. Technol., 22, 427 (1998).

3. F. Kargi and A.R. Dincer, Enzyme Microb. Technol., 19, 529 (1996).

4. S. Rosenberger, U. Kruger, R. Witzig, W. Manz, U. Szewzyk and M. Kraume, Water Res., 36, 413 (2002).

5. K. Kimura, H. Hara and Y. Watanabe, Desalination, 178, 135 (2005).

6. W.B. Yang, N. Cicek and J. Ilg, J. Membr. Sci., 270, 201 (2006).

7. D. Jeison, B. Kremer and J.B. van Lier, Sep. Purif. Technol., 64, 198 (2008).

8. X. Huang, K. Xiao and Y.X. Shen, Front. Environ. Sci. Eng. China, 4, 245 (2010).

9. S. Judd and S.W. Till, Desalination, 127, 251 (2000).

10. I.S. Chang, S.O. Bag and C.H. Lee, Process Biochem., 36, 855 (2001).

11. B. Jefferson and A.L. Laine, Water Sci. Technol., 41, 197 (2000).

12. C.-H. Wei, X. Huang, R. Ben Aim, K. Yamamoto and G. Amy, Water Res., 45, 863 (2011).

13. E.H. Bouhabila, R. Ben Aïm and H. Buisson, Desalination, 118, 315 (1998).

14. J.A. Howell, H.C. Chua and T.C. Arnot, J. Membr. Sci., 242, 13 (2004).

15. P. Le-Clech, B. Jefferson and S.J. Judd, J. Membr. Sci., 218, 117 (2003).

16. S. Rosenberger and M. Kraume, Desalination, 151, 195 (2003).

17. W. Lee, S. Kang and H. Shin, J. Membr. Sci., 216, 217 (2003).

18. H.S. Shin and S.T. Kang, Water Res., 37, 121 (2003).

19. E. Tardieu, A. Grasmick, V. Geaugey and J. Manem, J. Membr. Sci., 147, 1 (1998).

20. T. Zsirai, P. Buzatu, P. Aerts and S. Judd, Water Res., 46, 4499 (2012). 